\title{
Dyspepsia amongst end stage renal disease undergoing hemodialysis: Views from a large tertiary care center
}

\author{
Muhammad Ali Khalid, Jawaid Iqbal, Hassan Liaquat Memon, Farina M. Hanif, \\ Muhammad Osama Tariq Butt, Nasir Hassan Luck, Zain Majid \\ Department of Hepatogastroenterology, Sindh Institute of Urology and Transplantation, Karachi, Pakistan
}

\section{ABSTRACT}

Background and Objectives: Gastrointestinal symptoms are common in patients with end stage renal disease (ESRD) among which dyspepsia is frequently observed. The aim of the study was to determine the frequency and associations of dyspepsia in ESRD patients using the Leeds questionnaire. Methods: All ESRD patients on maintenance hemodialysis were consecutively enrolled in the study. Leeds questionnaire was used to interrogate the patients for the assessment of dyspepsia. Mean and standard deviation were calculated for age, body mass index (BMI), disease duration and number of hemodialysis sessions. Independent t-test and Chi square tests were used for statistical analysis. Results: Total number of patients was 200, out which 118 (59.3\%) were male. The mean age was of 41.4 years. According to the Leeds questionnaire, dyspepsia was present in $62(63.9 \%)$ patients. Younger patients (age 20-40 years) more frequently had dyspeptic symptoms (61.5\% patients), retrosternal pain (156 patients, $78.0 \%$ ), regurgitation (127 patients, $63.5 \%$ ), dysphagia (67 patients, $33.5 \%$ ), and nausea (142 patients, $71.0 \%$ ). Patients presented with intermittent pattern of symptoms in $179(89.5 \%)$ cases, while continuous symptoms in $6(3.0 \%)$. Dyspepsia was associated with aspartate aminotransferase (AST) levels $>25 \mathrm{U} / \mathrm{L}(P=0.001)$, alanine aminotransferase $(\mathrm{ALT})$ levels $>28 \mathrm{U} / \mathrm{L}(P=0.000)$ and gamma glutamyl transferase $(\mathrm{GGT})$ levels $>34 \mathrm{U} / \mathrm{L}(P=$ 0.002). On multivariate analysis, urea, creatinine, and presenting symptoms of dysphagia and belching showed significant statistical association with dyspepsia. Conclusion: Dyspepsia is a common problem affecting patients with end stage renal disease and is associated with raised serum AST, ALT and GGT in such patients.

Key words: end stage renal disease (ESRD), hemodialysis, dyspepsia, Leeds questionnaire, tertiary care center

\section{INTRODUCTION}

Address for Correspondence:

Hepatogastroenterology, Sindh Institute

of Urology and Transplantation, Karachi

Pakistan.

Email: zain88@hotmail.com

\begin{tabular}{|l|}
\hline Access this article online \\
Website: \\
www.intern-med.com \\
DOI: \\
10.2478/jtim-2018-0013 \\
\hline Quick Response Code: \\
\hline \\
\hline
\end{tabular}

Gastrointestinal symptoms are common amongst patients with end stage renal disease (ESRD). The most common gastrointestinal complaints in ESRD patients include heartburn, constipation, diarrhea and dyspepsia. ${ }^{[1]}$ Dyspepsia, a common gastrointestinal problem experienced by patients with ESRD, is defined as an upper abdominal pain or discomfort, bloating, early satiety, post prandial fullness, nausea with or without vomiting, anorexia, regurgitation and belching. Studies have suggested that dyspeptic symptoms are more prevalent amongst hemodialysis patients when compared to the general population. ${ }^{[2]}$ Despite its wide prevalence (48-70\%), dyspepsia amongst hemodialysis patients has not been thoroughly investigated. Local or systemic circulatory insufficiency, hypergastrinemia and higher levels of ammonia and inflammation have been attributed as the causes of gastric mucosal injury in ESRD. Among the general causes of impaired quality of life, dyspepsia has been shown as a contributing factor. ${ }^{[3]}$ Out of the various questionnaire available for its evaluation, the Leeds dyspepsia questionnaire (LDQ) has been recognized as a standard criterion for evaluation and assessment of dyspeptic symptoms in hemodialysis patients. The LDQ has a 
sensitivity of $80 \%$ and a specificity of $79 \%$ in the general population. ${ }^{[4]}$

Since dyspeptic symptoms have a detrimental effect on the quality of life and psychological well-being in ESRD patients, ${ }^{[5,6]}$ awareness of the prevalence of these symptoms would be crucial in improving the quality of life in this patient population.

\section{MATERIAL AND METHODS}

All patients between 16-55 years of age of either gender, on maintenance hemodialysis were consecutively enrolled in the study. The study was conducted at the Sindh Institute of Urology and Transplantation (SIUT), Karachi, Pakistan, a large tertiary care center that caters to a significant number of dialysis patients from all over Pakistan. Dyspepsia was labelled after using the LDQ questionnaire, in those with a score equal or greater than 5 over the period of last four weeks. ${ }^{[7]}$ Since the LDQ is long and cumbersome, and was not designed for self-completion, we modified the questionnaire for use in our setting. The LDQ questionnaire originally comprised of 9 questions in total. We modified it by omitting questions about the severity, grading and changing it to the presence and absence of symptoms (Figure 1).

Those excluded from this study were patients who failed to give an informed consent, the presence of disease or clinical situation like sepsis, cardiac disease or any psychiatric illness that could prevent patients from answering the questionnaires, patients who were already on proton pump inhibitors, diabetics, those with a history of abdominal surgery, patients who had an endoscopy in the past that revealed a gastric ulcer, inflammation or structural alterations. All the patients were evaluated and interviewed by the principal investigators themselves.

\section{Statistical analysis}

The collected data was then entered into SPSS (version 20.0) and the mean and standard deviation was calculated for continuous variables. While frequency and percentages were calculated for categorical variables. Effect modifiers like age, gender, duration of ESRD, duration of hemodialysis and BMI were stratified. Post stratification, chi square test was applied. A $P$ value $<0.05$ was considered as statically significant.

\section{RESULTS}

The total number of patients were 200, out which 118 $(59.3 \%)$ were males. The mean age was 41.4 years (range 14 78 years). According to the Leeds questionnaire, dyspepsia was present in $62(63.9 \%)$ patients. Younger patients (age
$20-40$ years) had more frequent dyspeptic symptoms. The clinical along with laboratory parameters of the studied population is depicted in Figure 1. The main presenting symptoms were retrosternal pain $(78.0 \%)$ followed by nausea $(71 \%)$ and regurgitation $(63.5 \%)$. Vomiting was the least common presenting symptom $(21 \%)$. The mean BMI reported was $22.08 \pm 3.6 \mathrm{~kg} / \mathrm{m}^{2}$. An intermittent pattern of symptoms was seen in 179 (89.5\%) cases, while continuous symptoms were noted in $6(3.0 \%)$. Laboratory evaluation showed a mean total bilirubin (mg/dL) $0.92 \pm 2.4 \mathrm{mg} / \mathrm{dL}$, mean alanine aminotransferase (ALT) was $34.7 \pm 38.7 \mathrm{mg}$ / $\mathrm{dL}$, mean aspartate aminotransferase (AST) was $31.1 \pm$ $23.3 \mathrm{mg} / \mathrm{dL}$, mean GGT was $43.5 \pm 37.06 \mathrm{mg} / \mathrm{dL}$, mean alkaline phosphate $137.0 \pm 91.9 \mathrm{mg} / \mathrm{dL}$, mean urea $(\mathrm{mg} /$ $\mathrm{dL})$ was $115.2 \pm 55.1 \mathrm{mg} / \mathrm{dL}$ and mean creatinine $(\mathrm{mg} /$ dL) $8.6 \pm 3.3 \mathrm{mg} / \mathrm{dL}$.

In order to evaluate the association of dyspepsia to the various measured parameters in our population, univariant analysis was performed (Figure 1). On univariant analysis, dyspepsia was associated with AST levels $>25 \mathrm{U} / \mathrm{L}(P$ $=0.001)$, ALT levels $>28 \mathrm{U} / \mathrm{L}(P=0.000)$, and gamma glutamyl transferase (GGT) levels $>34 \mathrm{U} / \mathrm{L}(P=0.002)$ (Table 1-5). While on multivariate analysis, urea, creatinine, presenting symptoms of dysphagia and belching showed a significant association with dyspepsia (Table 6).

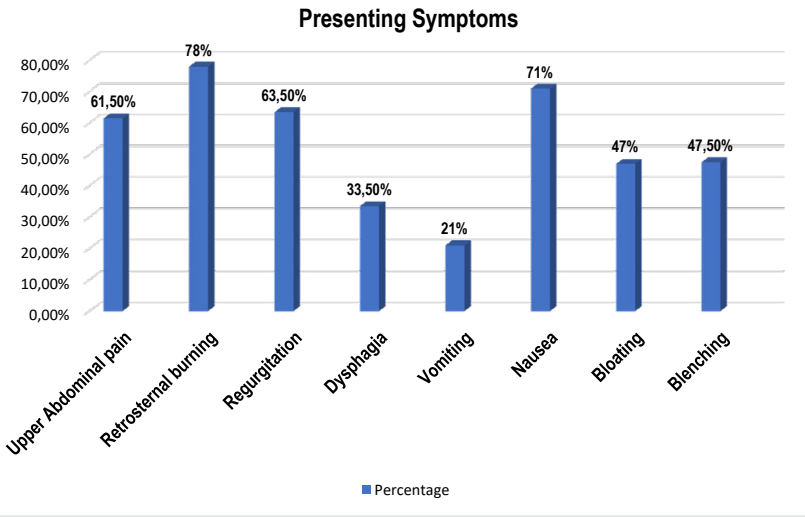

Figure 1: Distribution of presenting symptoms in hemodialysis patients with dyspepsia

\section{DISCUSSION}

Heartburn, constipation, diarrhea and dyspepsia are amongst the most common gastrointestinal complaints in ESRD patients. ${ }^{[1]}$ The prevalence of dyspepsia in hemodialysis (HD) patients varies between $48 \%$ and $70 \%,{ }^{[2,5,6]}$ which is consistent with the results seen in our study $\left(63.8 \%\right.$ of the population had dyspepsia). Strid et al. ${ }^{[8]}$ also documented a similar finding in their study, while comparing dyspeptic symptoms amongst the dialysis and 
Khalid et al.: Dyspepsia in end stage renal disease patients

\begin{tabular}{lll}
\hline \hline \multicolumn{1}{l}{ Table 1: Frequency of dyspepsia with respect to gender } \\
\hline Gender & Frequency $(\boldsymbol{n})$ & Percentage (\%) \\
\hline Male & 118 & 59.3 \\
Female & 82 & 40.7 \\
Total & 200 & 100 \\
\hline
\end{tabular}

\begin{tabular}{llll}
\hline \multicolumn{2}{l}{ Table 2: Stratification of dyspepsia with respect to gender } & \\
\hline Yes/No & $\begin{array}{l}\text { Dyspepsia }(\boldsymbol{n}) \\
\text { Yes/No }\end{array}$ & Total $(\boldsymbol{n})$ & $\boldsymbol{P}$ value \\
\hline Male & $75 / 43$ & 118 & 0.766 \\
Female & $50 / 32$ & 82 & 0.766 \\
Total & $125 / 75$ & 200 & 0.766 \\
\hline
\end{tabular}

Chi-square test applied.

\begin{tabular}{|c|c|c|c|}
\hline \multirow[t]{2}{*}{ Age } & Dyspepsia $(n)$ & Total $(n)$ & $P$ value \\
\hline & \multicolumn{3}{|l|}{ Yes/No } \\
\hline$<40$ & $61 / 41$ & 102 & 0.466 \\
\hline$>40$ & $64 / 34$ & 98 & 0.466 \\
\hline Total & $125 / 75$ & 200 & 0.466 \\
\hline
\end{tabular}

Chi-square test applied.

\begin{tabular}{llll}
\hline \multicolumn{2}{l}{ Table 4: Stratification of dyspepsia with respect to body mass index } & \\
\hline Body mass index & Dyspepsia $(\boldsymbol{n})$ & Total $(\boldsymbol{n})$ & $\boldsymbol{P}$ value \\
& Yes/No & & 0.141 \\
\hline$<22$ & $66 / 48$ & 114 & 0.141 \\
$>22$ & $59 / 27$ & 86 & 0.141 \\
\hline
\end{tabular}

Chi-square test applied.

\begin{tabular}{llll}
\hline \multicolumn{2}{l}{ Table 5: Stratification of dyspepsia with respect to duration } & \\
\hline Duration (months) & $\begin{array}{l}\text { Dyspepsia }(\boldsymbol{n}) \\
\text { Yes/No }\end{array}$ & Total $(\boldsymbol{n})$ & $\boldsymbol{P}$ value \\
\hline$<2$ & $13 / 13$ & 26 & 0.493 \\
$2-6$ & $59 / 32$ & 91 & 0.493 \\
$6-12$ & $25 / 12$ & 37 & 0.493 \\
$>12$ & $28 / 18$ & 46 & 0.493 \\
Total & $125 / 75$ & 200 & 0.493 \\
\hline
\end{tabular}

Chi-square test is applied.

\begin{tabular}{|c|c|c|c|c|c|}
\hline \multirow[t]{2}{*}{ Parameters } & Univariant & Multivariant & Parameters & Univariant & Multivariant \\
\hline & $P$ value & $P$ value & & $P$ value & $P$ value \\
\hline Abdominal Pain & 0.002 & 0.984 & Total BR & 0.205 & 0.632 \\
\hline Retrosternal Burning & 0.001 & 0.632 & DBR & 0.143 & 0.691 \\
\hline Regurgitation & 0.001 & 0.077 & ALT & 0.397 & 0.961 \\
\hline Dysphagia & 0.001 & 0.053 & AST & 0.001 & 0.966 \\
\hline Vomiting & 0.001 & 0.315 & ALT & 0.001 & 0.441 \\
\hline Nausea & 0.001 & 0.502 & GGT & 0.040 & 0.735 \\
\hline Blenching & 0.001 & 0.059 & Urea & 0.081 & 0.001 \\
\hline Bloating & 0.001 & 0.500 & Creatinine & 0.007 & 0.001 \\
\hline Pattern & 0.001 & 0.164 & $\mathrm{BMI}$ & 0.901 & 0.793 \\
\hline
\end{tabular}

ALT: alanine aminotransferase; AST: aspartate aminotransferase; GGT: gamma glutamyl transferase; BMI: body mass index; DBR: direct bilirubin; BR: bilirubin. 
predialysis patients group. Dyspepsia could have an organic or a functional cause, with the latter being more common in the HD patients in comparison to the general population.

Several questionnaires have been proposed in the past for the evaluation and assessment of dyspeptic symptoms in hemodialysis patients. After the execution of a number of cost effective randomized trials in the past regarding the dyspeptic investigations and treatment, the Leeds questionnaire has been recognized as the standard criterion for the evaluation of the frequency and severity of symptoms of dyspepsia amongst CKD patients. ${ }^{[9]}$

We used the Leeds questionnaire with slight modifications and instead of the usual 9 major questions, only 8 were retained and the grading system, that is, from mild to very severe was changed to the presence (Yes) and absence (No) of symptoms. In the studied population, the eight major complaints were of retrosternal pain $(78.0 \%)$, nausea $(71.0 \%)$, regurgitation $(63.5 \%)$, upper abdominal pain $(61.5 \%)$, belching $(47.5 \%)$, bloating (47\%), dysphagia $(33.5 \%)$ and vomiting $(21 \%)$.

Several studies have shown dyspepsia in ESRD patients to be a multifactorial phenomenon that include the increased levels of gastrin due to its reduced clearance in the chronic kidney disease patients and an increase in ammonia levels as a compensatory effect that occurs owing to the neutralization of the gastric juice. An increase in ammonia levels results in inflammation and gastric mucosal injury, which is seen more often in ESRD patients than in the general population. ${ }^{4}$ High prevalence of dyspepsia could also be due to the hypervolemic state in ESRD patients, which is considered as a modulator of gastric motility, thus leading to gastroparesis

Another crucial impact of dyspepsia is related to the nutritional state of the patient. In the general population, weight loss is taken as an alarm symptom that raises suspicion of organic disease.

However, weight loss also occurs in patients with dyspepsia. ${ }^{[10]}$ The most well-known factors associated with malnutrition in ESRD are anorexia and chronic inflammation. ${ }^{[1]]}$ In the past, hemodialysis has not been linked to malnutrition. According to the Third Conference on Nephrology held in Valencia, Spain, dyspeptic HD patients have a lower calorie and protein intake compared to non-dyspeptics.

A study conducted on the CKD patients with dyspepsia showed that a worsening serum creatinine is inversely related with gastroesophageal reflux disease (GERD) symptoms 11; this was the opposite of what was seen in our study.

\section{CONCLUSION}

Our result shows that the prevalence of dyspepsia was high in ESRD patients currently on hemodialysis. Usually, the younger patients were affected more. Retrosternal pain, regurgitation and upper abdominal pain were frequent presentations. No significant association of dyspepsia was found with age, gender, BMI and duration of symptoms.

\section{Conflict of Interest}

None declared.

\section{REFRENCES}

1. Shirazian S1, Radhakrishnan J. Gastrointestinal disorders and renal failure: exploring the connection. Nat Rev Nephrol 2010; 6: 480-92.

2. Sugimoto M1, Yamaoka Y. Review of Helicobacter pylori infection and chronic renal failure. Ther Apher Dial 2011; 15: 1-9.

3. Aro P1, Talley NJ, Agréus L, Johansson SE, Bolling-Sternevald E, Storskrubb T, et al. Functional dyspepsia impairs quality of life in the adult population. Aliment Pharmacol Ther 2011; 33: 1215-24.

4. Moayyedi P1, Duffett S, Braunholtz D, Mason S, Richards ID, Dowell AC, et al. The Leeds Dyspepsia Questionnaire: a valid tool for measuring the presence and severity of dyspepsia. Aliment Pharmacol Ther 1998; 12: 1257-62.

5. Aro P1, Talley NJ, Agréus L, Johansson SE, Bolling-Sternevald E, Storskrubb T, et al. Functional dyspepsia impairs quality of life in the adult population. Ronkainen J Aliment Pharmacol Ther 2011; 33: 1215-24.

6. Strid H1, Simrén M, Johansson AC, Svedlund J, Samuelsson O, Björnsson ES. The prevalence of gastrointestinal symptoms in patients with chronic renal failure is increased and associated with impaired psychological general well-being. Nephrol Dial Transplant 2002; 17: 1434-9.

7. Bacci MR, Chehter EZ. Dyspepsia among patients with chronic kidney disease: a cross sectional study. Int Arch Med 2013; 6: 43.

8. Salles Jr LD, Santos PR, Santos AA, Souza MHLP. Dyspepsia and gastric emptying in end-stage renal disease patients on hemodialysis. BMC Nephrology 2013; 14: 275.

9. Louis E1, Tack J, Vandenhoven G, Taeter C. Evaluation of the GERD Impact Scale, an international, validated patient questionnaire, in daily practice. Results of the ALEGRIA study. Acta Gastroenterol Belg 2009; 72: 3-8.

10. Bossola M, Muscaritoli M, Tazza L, Panocchia N, Liberatori M, Giungi $\mathrm{S}$, et al. Variables associated with reduced dietary intake in hemodialysis patients. J Renal Nutr 2005; 15: 244-52.

11. Santos PR. Dyspepsia: an underestimated problem among end-stage renal disease patients. In: Third International Conference on Nephrology \& Therapeutics, June 26-27, 2014, Valencia Conference Centre, Valencia, Spain.

How to cite this article: Khalid MA, Iqbal J, Memon HL, Hanif FM, Tariq Butt MO, Luck NH, et al. Dyspepsia amongst end stage renal disease undergoing hemodialysis: Views from a large tertiary care center J TransI Intern Med 2018; 6: 78-81. 